\title{
Mannose receptor interacts with Fc receptors and is critical for the development of crescentic glomerulonephritis in mice
}

\author{
Konstantia-Maria Chavele, ${ }^{1}$ Luisa Martinez-Pomares, ${ }^{2}$ Jan Domin, ${ }^{1}$ \\ Samantha Pemberton, ${ }^{3}$ Stuart M. Haslam, ${ }^{3}$ Anne Dell, ${ }^{3} \mathrm{H}$. Terence Cook, ${ }^{4}$ \\ Charles D. Pusey, ${ }^{1}$ Siamon Gordon, ${ }^{5}$ and Alan D. Salama ${ }^{1}$
}

\begin{abstract}
${ }^{1}$ Renal Section, Division of Medicine, Imperial College London, Hammersmith Hospital, London, United Kingdom. ${ }^{2}$ School of Molecular Medical Sciences, Queen's Medical Centre, University of Nottingham, Nottingham, United Kingdom. ${ }^{3}$ Division of Molecular Biosciences, Faculty of Natural Sciences, Imperial College London, London, United Kingdom. ${ }^{4}$ Department of Histopathology, Imperial College London, Hammersmith Hospital, London, United Kingdom. ${ }^{5}$ Sir William Dunn School of Pathology, University of Oxford, Oxford, United Kingdom.
\end{abstract}

\begin{abstract}
Crescentic glomerulonephritis (CGN), which frequently results in acute and chronic kidney disease, is characterized by and dependent on glomerular infiltration by macrophages. The mannose receptor (MR) is a pattern recognition receptor implicated in the uptake of endogenous and microbial ligands by macrophages, mesangial cells (MCs), and selected endothelial cells. It is upregulated on alternatively activated macrophages (i.e., macrophages associated with tissue repair and humoral immunity) and involved in antigen presentation to $T$ cells. We used the mouse model of nephrotoxic nephritis to investigate the role of MR in CGN. Our results demonstrate what we believe to be a novel role for MR in the promotion of CGN that is independent of adaptive immune responses. MR-deficient $\left(\mathrm{Mr}^{-/-}\right)$mice were protected from CGN despite generating humoral and $T$ cell responses similar to those of WT mice, but they demonstrated diminished macrophage and MC Fc receptor-mediated (FcR-mediated) functions, including phagocytosis and Fc-mediated oxygen burst activity. $\mathrm{Mr}^{-/-}$MCs demonstrated augmented apoptosis compared with WT cells, and this was associated with diminished Akt phosphorylation. Macrophage interaction with apoptotic MCs induced a noninflammatory phenotype that was more marked in $\mathrm{Mr}^{-/-}$macrophages than in WT macrophages. Our results demonstrate that MR augments Fc-mediated function and promotes MC survival. We suggest that targeting MR may provide an alternative therapeutic approach in CGN while minimizing the impact on adaptive immune responses, which are affected by conventional immunosuppressive approaches.
\end{abstract}

\section{Introduction}

Crescentic glomerulonephritis (CGN), in association with primary systemic vasculitis or SLE, frequently results in endstage kidney disease despite immunosuppressive therapy $(1,2)$. Although numerous immune effectors, including antibodies, complement, and infiltrating lymphocytes, play a significant pathogenic role, it is monocytes and macrophages that appear to be key, since experimental disease is inducible in the absence of T cells $(3)$ or B cells $(4,5)$ but not macrophages $(6,7)$. Additionally, in patients with lupus glomerulonephritis, macrophage persistence follow immunosuppressive therapy is associated with poor long-term renal outcome (8). Macrophages migrate to and localize in and around the glomerulus, in response to chemokines produced after cell-mediated immune reactions or antibody deposition (9), promoting immune injury. Macrophages produce a variety of inflammatory molecules that cause renal injury and glomerular basement membrane (GBM) damage, such as proteolytic enzymes, ROS, and NO (10). However, alternative states of macrophage activation exist, and although some macrophages may display proinflammatory phenotypes, others may be associated with more reparative profiles, such as in the case of alternatively activated macrophages (11). This diversity may explain data showing that experimental disease

Conflict of interest: The authors have declared that no conflict of interest exists. Citation for this article: J Clin Invest. 2010;120(5):1469-1478. doi:10.1172/JCI41560. can be abrogated despite similar degrees of glomerular macrophage infiltration (12). Defining these phenotypic variants and how they may be induced is an important step in altering the outcome of experimental and human glomerulonephritis.

Glomerular injury involves both infiltration by circulating leukocytes and proliferation of resident glomerular cells, in particular mesangial cells (MCs), and regulation of this process may influence the outcome of glomerulonephritis (13, 14). Indeed, the interaction between resident and infiltrating cells may be bidirectional, with MCs influencing the fate and phenotype of infiltrating macrophages through local cytokine and chemokine production (15). This in turn can determine the inflammatory response and skew its outcome toward resolution or scarring. However, to our knowledge, a critical role for MCs in directing this outcome in nephrotoxic nephritis (NTN) has not hitherto been described.

The mannose receptor (MR) is one of the prototypic markers of alternatively activated macrophages. It is a $175-\mathrm{kDa}$ transmembrane protein that contains an $\mathrm{N}$-terminal cysteine-rich domain, a single fibronectin type II domain, 8 C-type lectin-like domains (CTLDs), a transmembrane region, and a short cytoplasmic tail. Although MR is widely expressed by tissue macrophages, its expression in normal murine kidney is restricted to MCs (16). MR is also expressed by subsets of dendritic cells that mediate antigen uptake, leading to enhanced presentation to T cells (17). The MR is a lectin scavenger receptor implicated in clearance of 
A

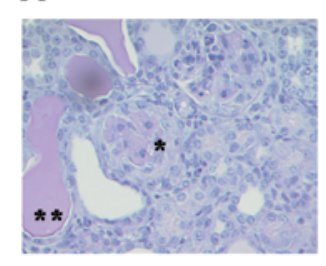

B

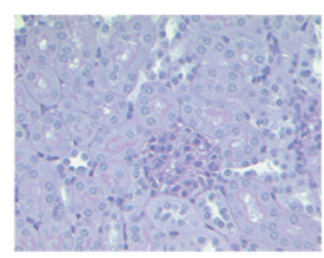

\section{C}

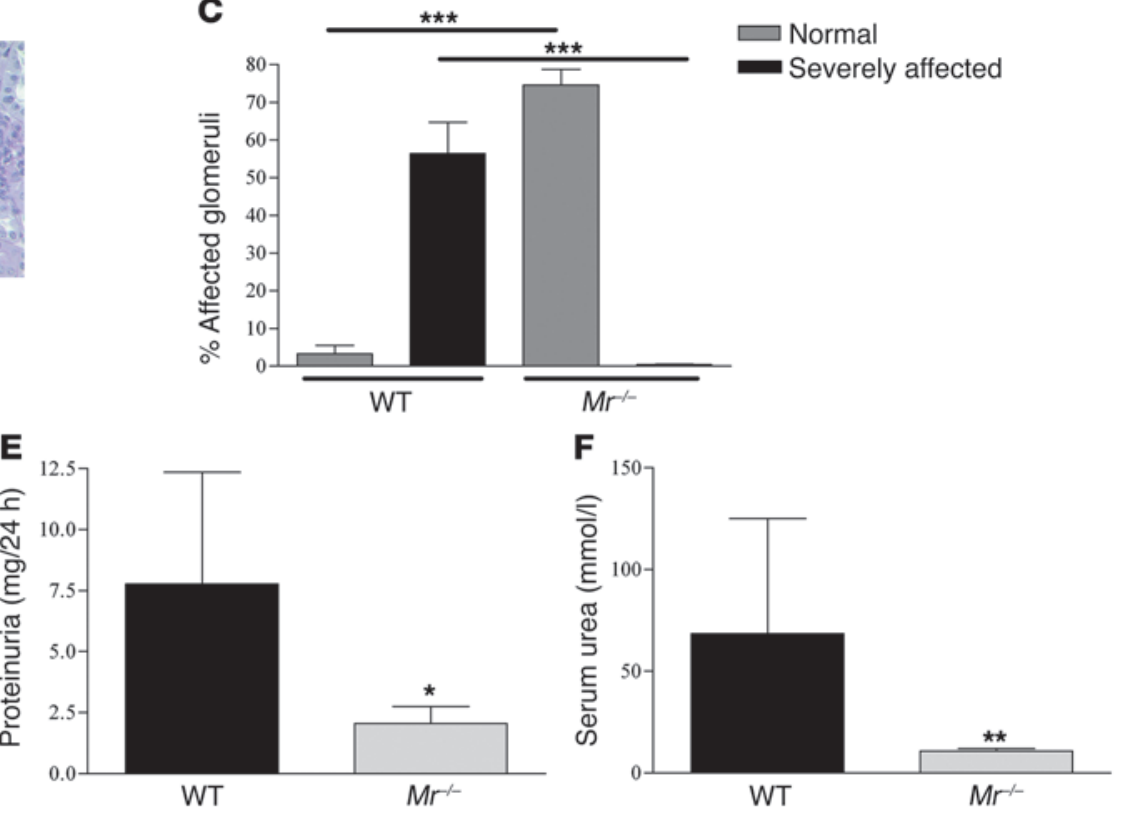

$\mathbf{F}$
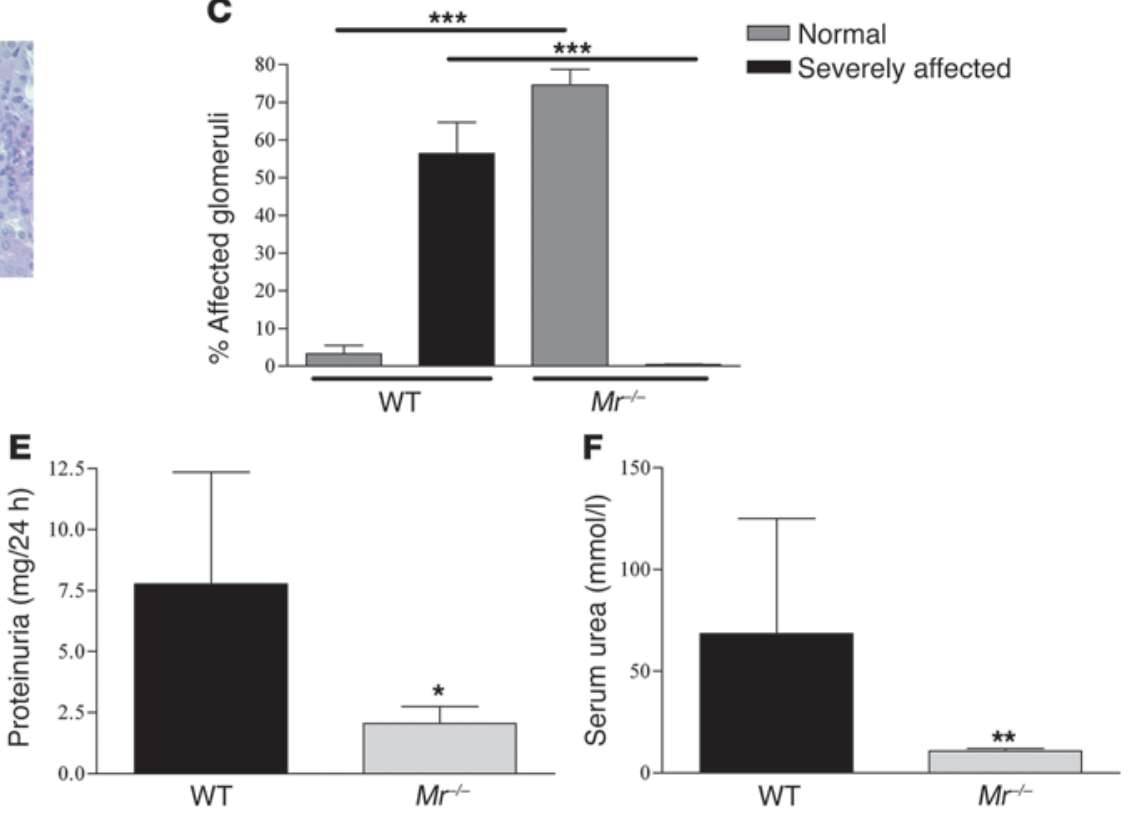

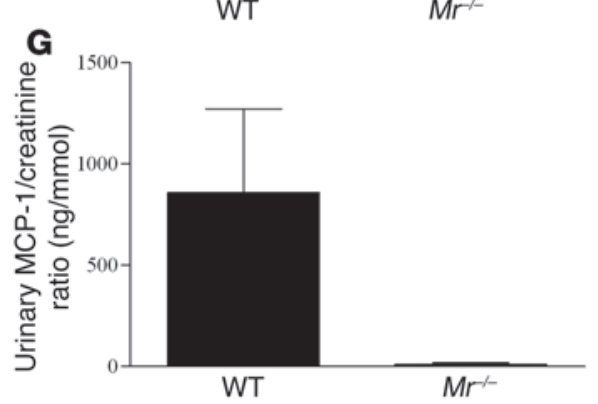

D

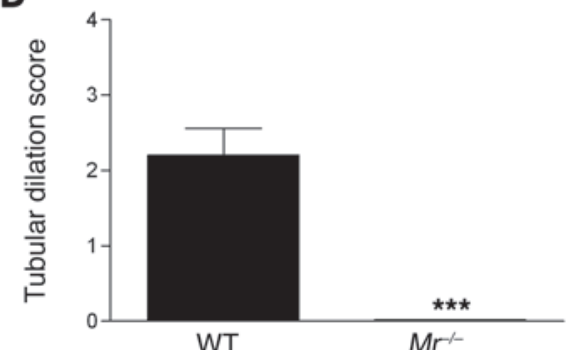

Figure 1

Assessment of NTN in WT and $\mathrm{Mr}^{-1-}$ mice 8 days after disease induction. (A and B) Renal histology from WT and $M r^{-1-}$ mice with NTN. Representative sections from (A) WT and (B) $\mathrm{Mr}^{-1-}$ mice with periodic acid-Schiff staining, demonstrating CGN (single asterisk) and severe tubulointerstitial injury (double asterisk) with dilated tubules and cast formation. Original magnification, $\times 200$. (C-G) Disease severity was assessed by measurement of (C) histological glomerular involvement, (D) tubular dilatation, (E) proteinuria, (F) serum urea, and (G) urinary MCP-1 excretion, normalized for creatinine. In all cases, WT mice exhibited severe disease, whereas $M r^{-1}$ mice were significantly protected. ${ }^{\star} P<0.05 ;{ }^{\star \star} P<0.01 ;{ }^{* \star \star} P<0.001$.

endogenous molecules, such as lysosomal hydrolases, produced during inflammation. MR is capable of binding several autoantigens, including myeloperoxidase and collagen IV (18), which are implicated in primary systemic vasculitis and anti-GBM disease, respectively, as well as glycosylated Igs (19), which are implicated in generation of CGN. In addition, MR ligation may enhance Fc-mediated responses (20), although interaction between Fc receptors ( $\mathrm{FcRs}$ ) and MR has not been extensively investigated. This is of interest, as we and others have previously demonstrated a vital role for FcRs in induction of CGN (21). However, in spite of its ability to recognize numerous pathogens, such as Candida albicans, Pneumocystis jiroveci, and dengue virus, MR deficiency in mice does not impair host responses to infections with $C$. albicans (22), P. jiroveci (23), or Leishmania (24).

In the present study, we describe what we believe to be a novel role for the MR in glomerular inflammation. MR-deficient $\left(\mathrm{Mr}^{-1}\right)$ animals were protected from NTN, despite similar antibody and $\mathrm{T}$ cell responses, and this protection was dependent on altered Fcmediated responses and antiinflammatory macrophage generation after interaction with MCs.

\section{Results}

$M R$ deficiency protects mice from developing renal injury and preserves renal function. Accelerated NTN was induced in WT and $\mathrm{Mr}^{-1-}$ female mice ( $n=9$ per group). After disease induction, WT mice developed renal impairment and proteinuria, with evidence of CGN and severe tubulointerstitial inflammation, whereas $\mathrm{Mr}^{-/-}$ mice were protected, with preserved renal function and mild glomerular hypercellularity (Figure 1, A-D). Renal histology demonstrated that WT mice had a significantly higher percentage of severely affected crescentic and thrombotic glomeruli compared with $\mathrm{Mr}^{-1-}$ mice (56.4 \pm 25 vs. $0 ; P<0.0001$; Figure $\left.1 \mathrm{C}\right)$, with a greater thrombosis score per glomerulus $(2.45 \pm 0.97$ vs. $0.3 \pm 0.25$; $P=0.0005)$ as well as greater tubular dilatation (2.2 \pm 1.1 vs. 0 ; $P<0.0001$; Figure 1D) and cast formation. Compared with $\mathrm{Mr}^{-/}$mice, WT mice had higher levels of proteinuria $(7.7 \pm 4.5 \mathrm{vs} .2 .0 \pm 2.1 \mathrm{mg} /$ $24 \mathrm{~h} ; P=0.01$; Figure $1 \mathrm{E})$, serum urea $(68.4 \pm 56.6$ vs. $10.6 \pm 3.6$ $\mathrm{mmol} / \mathrm{l} ; P=0.003$; Figure $1 \mathrm{~F})$, and serum creatinine ( $87.5 \pm 72.4$ vs. $33.3 \pm 3.6 \mu \mathrm{mol} / 1$; data not shown). Disease activity was also assessed by measuring urinary MCP-1 levels, which were previously shown to reflect the severity of human and rodent glomerulone- 
A

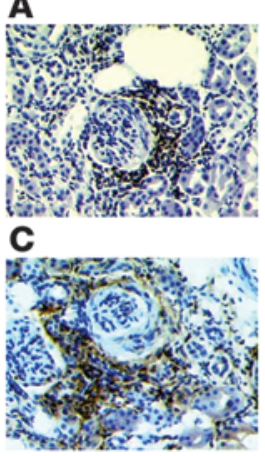

E

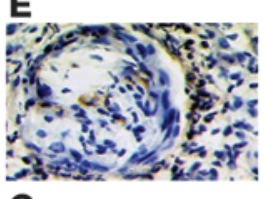

G

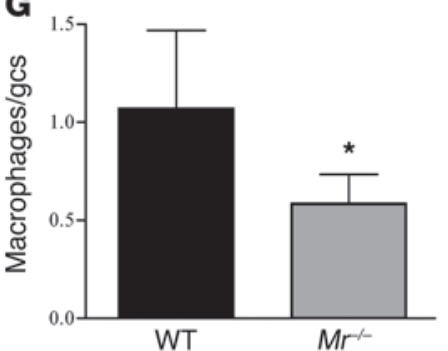

H

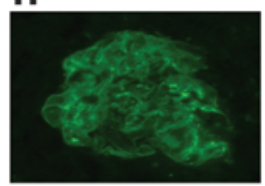

$\mathbf{K}$

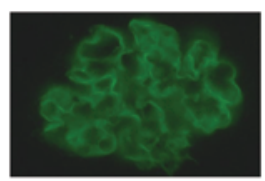

I

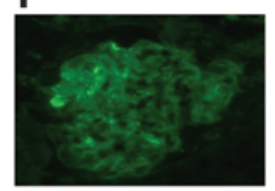

$\mathbf{L}$

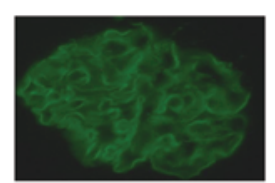

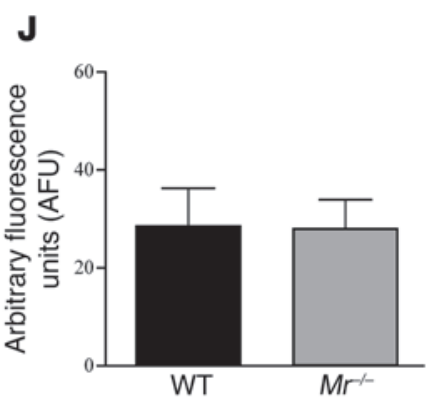
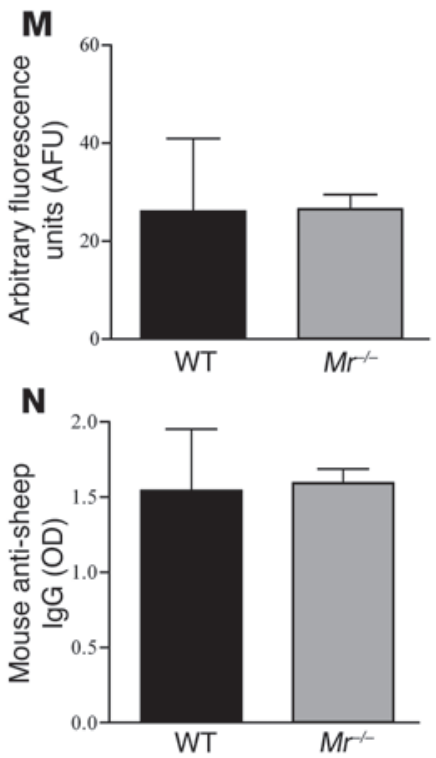

Figure 2

Immunohistochemical analysis of renal tissue from WT and $\mathrm{Mr}^{-1-}$ mice with NTN examined at day 8 after disease induction. (A-F) MHC class II expression (A and $\mathbf{B}), \mathbf{C D} 4^{+}$T cells ( $\mathbf{C}$ and $\left.\mathbf{D}\right)$, and $\mathbf{F A}-11$-positive macrophages (E and $\left.\mathbf{F}\right)$ demonstrated greater infiltration and expression in WT animals (A, C, and E) than their $\mathrm{Mr}^{-1-}$ counterparts (B, D, and $\left.\mathbf{F}\right)$. (G) Total number of macrophages, averaged per glomerular cross-section (gcs), demonstrated a small but significant decrease in $\mathbf{M r}^{-1-}$ versus WT animals. (H-J) Deposited mouse Ig in representative glomeruli from WT (H) and $\mathbf{M r}^{-1-}$ (I) mice, and quantification using image analysis (J), demonstrated equivalence. (K-M) Similarly, deposited sheep Igs in WT (K) and $\mathrm{Mr}^{-1-}(\mathbf{L})$ animals and the image analysis quantification (M) demonstrated equivalent degrees of binding to the GBM in both sets of animals. (N) Circulating mouse anti-sheep antibody levels were also equivalent between WT and $\mathrm{Mr}^{-1-}$ animals. Original magnification, $\times 200(\mathbf{A}-\mathbf{D}) ; \times 400$ (E, F, H, I, K, and L). * $P<0.05$.

phritis $(25,26)$. Whereas WT mice had significantly elevated levels of urinary MCP-1, $\mathrm{Mr}^{-/}$mice had very little cytokine detectable $(858.9 \pm 412.8$ vs. $10.52 \pm 8.3 \mathrm{pg} / \mathrm{ml} ; P=0.0008$; Figure $1 \mathrm{G})$.

We performed a time course experiment to follow the expression of MR and infiltrating macrophages in WT and $\mathrm{Mr}^{/-}$mice $(n=5$ per group). Prior to induction of glomerulonephritis in WT mice, MR expression was seen only within glomeruli, in a MC distribution (Supplemental Figure 1A; supplemental material available online with this article; doi:10.1172/JCI41560DS1), with no evidence of renal dendritic cell expression, as in previously reports (27). After injection of nephrotoxic serum, there was evidence of glomerular and tubular inflammation within 48 hours, and macrophage influx began by 72 hours. MR expression at 72 hours was no longer found in the glomerulus, but was in a periglomerular distribution, similar to that of infiltrating macrophages (Supplemental Figure 1B).

Immunohistochemistry of kidneys taken at day 8 after NTN induction ( $n=9$ per group) demonstrated that WT mice had higher levels of MHC class II expression within the kidney as well as greater $\mathrm{CD}^{+} \mathrm{T}$ cell and macrophage infiltration $(1.1 \pm 0.4$ vs.
$0.5 \pm 0.5$ cells/glomerular cross-section; $P=0.03$ ) compared with $\mathrm{Mr}^{-1-}$ mice (Figure 2, A-G). In contrast, glomerular sheep and mouse Igs were found to be deposited to the same extent in WT and $\mathrm{Mr}^{-1-}$ mice (Figure 2, H-M). Furthermore, no significant difference between groups was found in serum mouse anti-sheep IgG levels (Figure 2N) or in any anti-sheep IgG subclass (Supplemental Figure 2, A-D), as measured by ELISA. By day 8, the WT mice had greater degrees of C3 deposition; however, this reflected deposition in inflamed glomeruli, almost certainly the result of activation of the alternative pathway by tissue damage. Conversely, at the early day-4 time point, we found equivalent degrees of C3 staining between the WT and $\mathrm{Mr}^{-/}$animals ( $n=3$ per group). These data indicate that $\mathrm{Mr}^{-/}$mice showed no substantial defects in binding of the nephrotoxic serum to glomerular antigens, or in the humoral immune response to the planted sheep IgG. Additionally, no difference was found between WT and $\mathrm{Mr}^{-1-}$ mice in delayedtype hypersensitivity (DTH; measured by changes in skin thickness after intradermal antigen inoculation), in $\mathrm{T}$ cell proliferation in response to mitogen or sheep IgG, or in IL-17 production from 
A

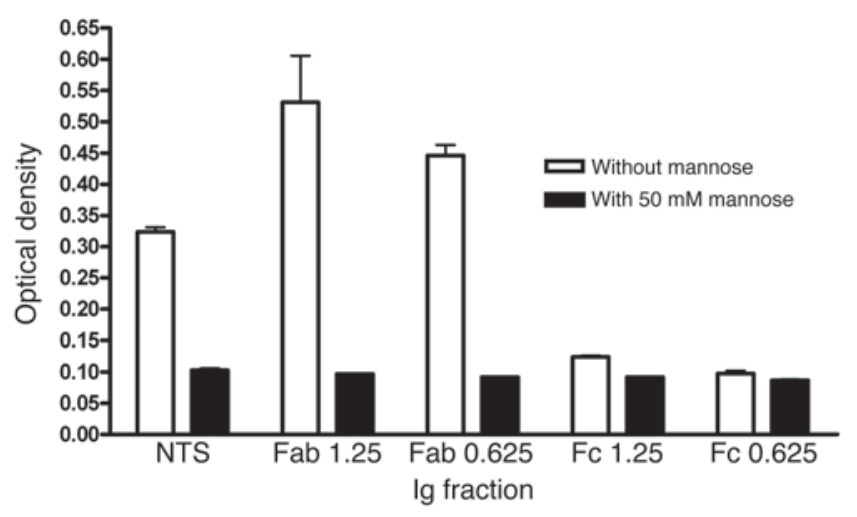

B
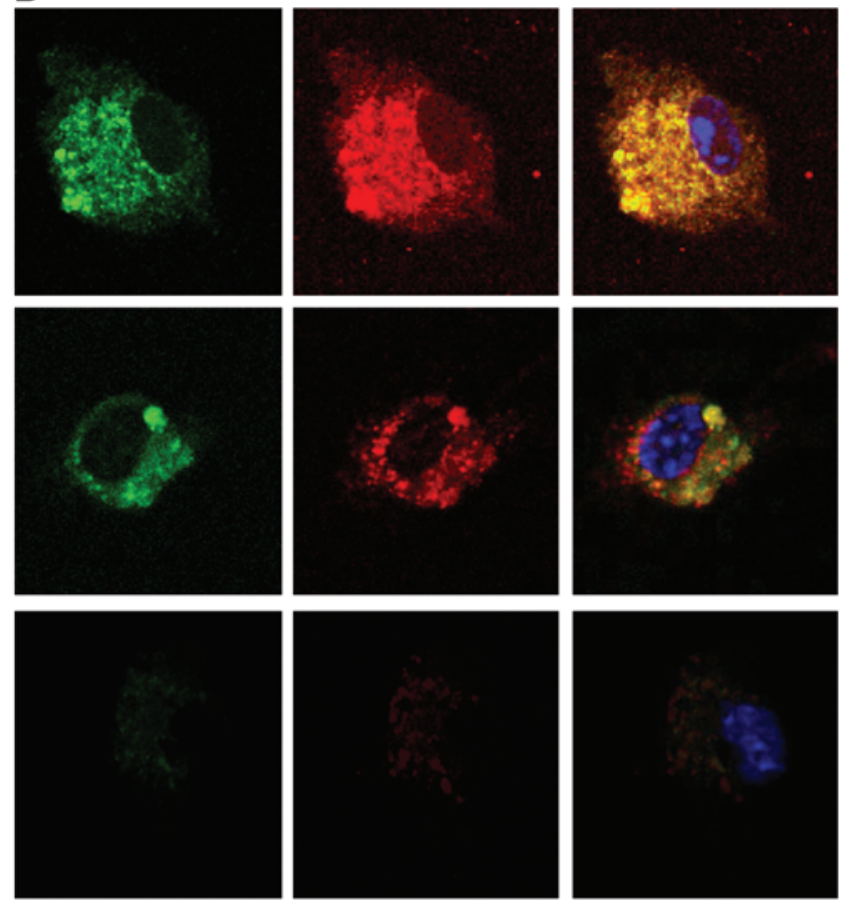

Figure 3

Interaction of MR and FcR. (A) The binding of whole sheep nephrotoxic globulin as well as its Fab and Fc fragments (at 1.25-and 0.625- $\mu \mathrm{g} / \mathrm{ml}$ concentrations) to chimeric molecules containing the different MR binding domains demonstrated binding to the Fab fragment in a dose-dependent manner, which was almost completely abolished by $50 \mathrm{mM}$ mannose. (B) Colocalization of Fc $\gamma \mathrm{R}$ (green) and MR (red) on unstimulated macrophages (top) and aggregated IgG-stimulated macrophages (middle). Isotype control antibody staining is shown below. Original magnification, $\times 600$.

purified $\mathrm{CD}^{+} \mathrm{T}$ cells stimulated with $\mathrm{CD} 3 / \mathrm{CD} 28$-coated microbeads (Supplemental Figure 3, A and B, and data not shown). Taken together, these data demonstrate that adaptive immune responses were equivalent in the WT and $\mathrm{Mr}^{-1}$ animals.

To exclude an effect of altered glycosylation patterns of IgG in $\mathrm{Mr}^{-1-}$ mice, we used mass spectroscopy to examine the sugar moieties attached to protein G-purified serum IgG from WT and $\mathrm{Mr}^{-1-}$ mice before and after induction of NTN. No substantive differences in the patterns of N-glycosylation were observed between WT and $\mathrm{Mr}^{-1-}$ mice (Supplemental Figure 4, A and B), with all samples demonstrating some high mannose N-glycans, but predominantly complex glycans, the most abundant having terminal GlcNAc residues. These data confirm that circulating murine IgG contains glycans capable of binding MR. In addition, we found similar glycosylation patterns on the sheep nephrotoxic serum (data not shown).

To further investigate the potential interaction between Igs and MR, we used chimeric molecules expressing the MR binding domains to test whether the Ig fraction of the nephrotoxic sheep serum would bind MR and which part would be responsible. We isolated the constituent Fc or Fab components of the sheep Ig and performed binding assays in the presence or absence of blocking sugar. These binding assays demonstrated that the CTLDs of the MR bound the Fab portion of sheep Ig and not the Fc portion, and this binding was inhibited in the presence of mannose (Figure 3A). The cysteine-rich domain and fibronectin domain did not bind any of the Ig fractions (data not shown). Taken together, these data demonstrate that glycosylated Igs can bind MR through appropriate carbohydrate binding regions.
Finally, we investigated whether MR and FcR colocalize in macrophages by performing immunofluorescence and confocal microscopy. We found that at rest and after stimulation with aggregated sheep Ig, MR and FcR colocalized in macrophages (Figure 3B).

$M R$ deficiency alters FcR function in macrophages and MCs. To study the effect of MR deficiency on FcR function, WT and $\mathrm{Mr}^{-/}$macrophages and MCs were examined using fluorescently labeled immune complexes or Ig-coated microbeads. Fc-mediated oxygen burst activity was assessed by incubating macrophages or MCs with Fc-OxyBURST (see Methods). WT and $\mathrm{Mr}^{-1-}$ macrophages expressed similar levels of Fc $\gamma \mathrm{RII} / \mathrm{III}$, as assessed by flow cytometry, whereas WT and $\mathrm{Mr}^{-/} \mathrm{MCs}$ also expressed similar levels of Fc $\gamma$ RIII, as assessed by qRT-PCR and flow cytometry, although these levels were significantly lower than those in macrophages (Figure 4, A and B). WT macrophages demonstrated greater initial fluorescence compared with $\mathrm{Mr}^{-/-}$macrophages $(P<0.0003$; Figure $4 C)$ and greater Fc-mediated oxygen burst activity over time, with a significantly greater calculated AUC (WT, $\left.8,587 \pm 1,313 ; \mathrm{Mr}^{-/}, 4,441 \pm 1,180 ; P=0.016\right)$. FC-mediated oxygen burst was also studied in WT and $\mathrm{Mr}^{/-} \mathrm{MCs}$, which showed an uptake response less rapid than that of macrophages, but a similar effect in WT- and $\mathrm{Mr}^{-/}$-derived cells (AUC, WT, 1,132 \pm 506 ; $\mathrm{Mr}^{-/}$, $959 \pm 400$; $P=0.0076$; Figure 4D). To confirm this effect, we performed another Fc-dependent assay testing the phagocytosis of opsonized polystyrene microbeads. Again, WT macrophages demonstrated greater bead uptake at 2 different bead concentrations compared with $\mathrm{Mr}^{-1}$ macrophages $(P<0.0001$; Figure 4E). These data demonstrate that $\mathrm{Mr}^{-1-}$ macrophages and MCs have diminished Fc-mediated phagocytosis and oxygen burst despite their similar numbers of FcRs. 
A

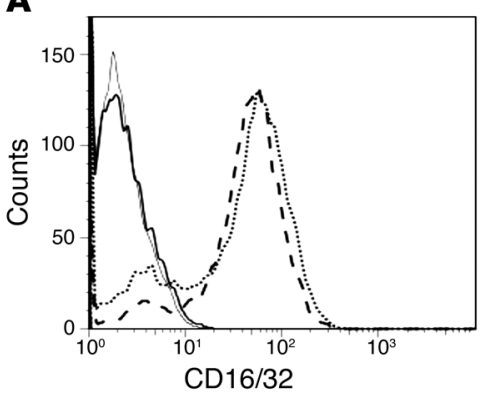

D

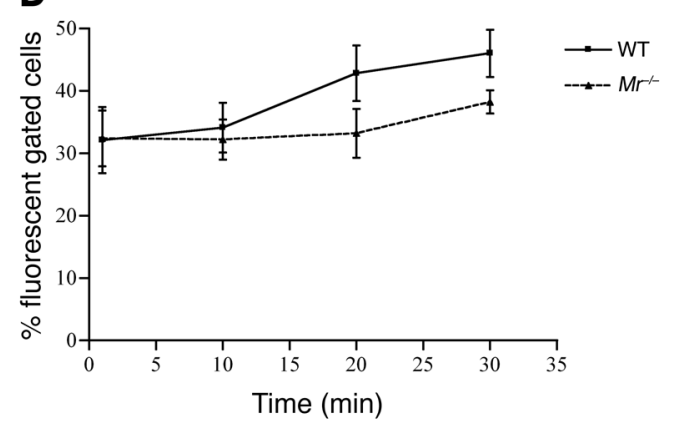

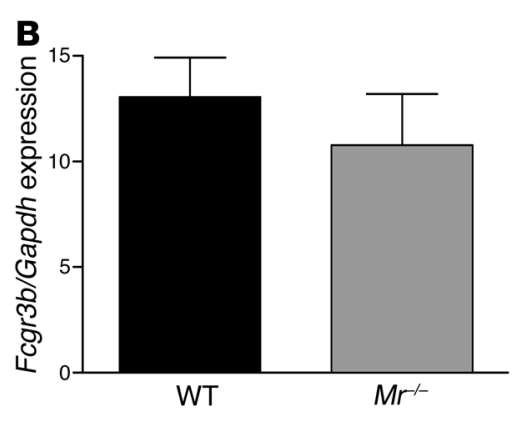

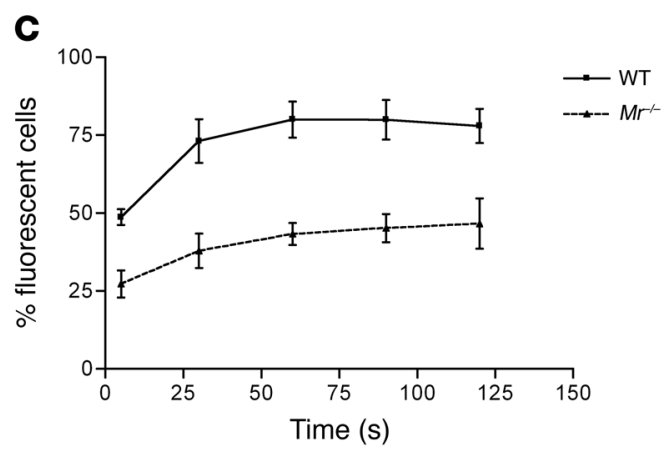

E

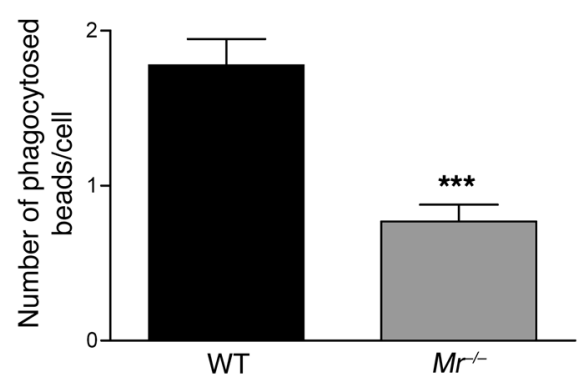

Figure 4

MR deficiency in MCs diminishes Fc-mediated oxygen burst activity and phagocytosis. Bone marrow-derived macrophages were cultured from WT and $\mathrm{Mr}^{-1-}$ mice. (A) CD16/CD32 expression, as measured by flow cytometry, showed no difference between WT (dotted line) and $\mathrm{Mr}^{-1-}$ (dashed line) cells. Solid gray and black lines denote isotype controls. (B) Real-time PCR expression of MC Fc $\mathrm{RIII}^{-1}$ in WT and $\mathrm{Mr}^{-1-}$ cells. (C) Fc-mediated oxygen burst activity, assessed in WT and $\mathrm{Mr}^{-1-}$ macrophages over time, demonstrated diminished Fc-mediated oxygen burst activity in $\mathrm{Mr}^{-1-}$ compared with WT cells. Shown is a representative experiment with 5 replicates per group. (D) FcR-mediated phagocytosis and oxygen burst activity, assessed in WT and $\mathrm{Mr}^{-1-} \mathrm{MC}$ s over time, demonstrated diminished Fc-mediated oxygen burst activity in $\mathrm{Mr}^{-1-}$ versus WT cells. Shown is a representative experiment with 4 replicates per group. (E) Microbead phagocytosis was performed and compared between $\mathrm{Mr}^{-1}$ and WT macrophages. There was significantly less uptake of microbeads in $\mathrm{Mr}^{-1-}$ compared with WT cells. ${ }^{* \star *} P<0.001$.

$M R$ deficiency induces angmented MC proliferation and apoptosis. We noticed that during standard culture conditions, $\mathrm{Mr}^{-/} \mathrm{MCs}$ proliferated at a greater rate than did WT cells. The increased proliferation rate was confirmed by tritiated thymidine uptake $\left(\mathrm{Mr}^{-/}\right.$, $189,064 \pm 20,663 \mathrm{cpm}$; WT, 93,004 $\pm 8,386 \mathrm{cpm} ; P=0.0014$; Figure 5A). In addition, unstimulated $\mathrm{MCs}$ from $\mathrm{Mr}^{-1-}$ mice underwent a greater degree of spontaneous apoptosis than did their WT counterparts $\left(7.99 \% \pm 1.5 \%\right.$ vs. $4.3 \% \pm 0.7 \%$ annexin $\mathrm{V}^{+} ; P<0.008$; Figure $\left.5 \mathrm{~B}\right)$. To validate these findings, MC lysates were used to assess Akt phosphorylation ( $\mathrm{p}-\mathrm{Akt})$, which plays a pivotal role in regulating cell survival and inhibiting apoptosis. $\mathrm{Mr}^{-/} \mathrm{MCs}$ expressed less p-Akt, both at basal levels and after stimulation with 10\% FCS (a known stimulus for p-Akt expression), compared with WT MCs (Figure 5, $\mathrm{C}$ and $\mathrm{D})$. Apoptosis was additionally confirmed in vitro using Hoechst dye in WT and $\mathrm{Mr}^{-/-} \mathrm{MCs}$ (Supplemental Figure 5, A and B). To examine the in vivo effect, we performed TUNEL staining in nephritic kidney sections and found increased numbers of glomerular cells undergoing apoptosis in $\mathrm{Mr}^{-/}$versus WT mice (14.8 $\pm 5.1 \mathrm{vs.}$ $4.5 \pm 4.4$ cells/glomerular cross-section; $P<0.016$; Figure $5 \mathrm{E})$.

Macrophage MR deficiency causes a shift to an antiinflammatory phenotype after interaction with apoptotic MCs. Previous reports have demonstrated induction of antiinflammatory macrophage phenotypes after ingestion of apoptotic human neutrophils $(28,29)$. Because MR deficiency induced greater MC apoptosis, we studied the role of MR in induction of antiinflammatory macrophage phenotypes. After incubation of macrophages with LPS, $\mathrm{Mr}^{-/}$- cells produced less TNF- $\alpha$ than did
WT cells over a range of concentrations (Supplemental Figure 6). Exposure of macrophages to LPS and apoptotic WT MCs resulted in reduced TNF- $\alpha$ expression compared with cells stimulated with LPS alone $\left(P<0.05\right.$, both WT and $\left.\mathrm{Mr}^{-/}\right)$. However, this effect was significantly more marked in $\mathrm{Mr}^{-/}$than WT macrophages (133 \pm 24 vs. $190 \pm 13.7 \mathrm{pg} / \mathrm{ml} ; P=0.0095$; Figure 6A). Levels of IL-10 were elevated after exposure to apoptotic cells $\left(P<0.05\right.$, both $\mathrm{Mr}^{-/}$and WT), and again were greater in $\mathrm{Mr}^{-1}$ compared with WT macrophages $(240 \pm 54$ vs. $199 \pm 22.9 \mathrm{pg} / \mathrm{ml} ; P=0.0095$; Figure 6B). However, TGF- $\beta$ levels were equally diminished in $\mathrm{Mr}^{-/-}$and WT macrophages following apoptotic cell exposure $\left(P<0.05\right.$, both WT and $\mathrm{Mr}^{-1}$; Figure $6 \mathrm{C})$. TNF- $\alpha / \mathrm{IL}-10$ and TNF- $\alpha /$ TGF- $\beta$ ratios after exposure to apoptotic MCs diminished significantly more in $\mathrm{Mr}^{-/-}$than in WT macrophages $(0.86 \pm 0.08$ vs. $0.48 \pm 0.06$ and $4.6 \pm 1.04$ vs. $6.4 \pm 0.7$, respectively; $P=0.0095$ for both; Figure $6, \mathrm{D}$ and $\mathrm{E}$ ).

\section{Discussion}

These data demonstrated that during glomerulonephritis, WT MCs expressing MR underwent diminished apoptosis, whereas macrophages and MCs demonstrated augmented Fc-mediated function and promotion of proinflammatory macrophages. In contrast, where MR was deficient, MCs underwent increased apoptosis, whereas macrophages had diminished Fc-mediated function, and the interaction of the 2 cells led to a predominant less-inflammatory macrophage phenotype, which may contribute to the disease protection found in $\mathrm{Mr}^{-/-}$mice. 
A

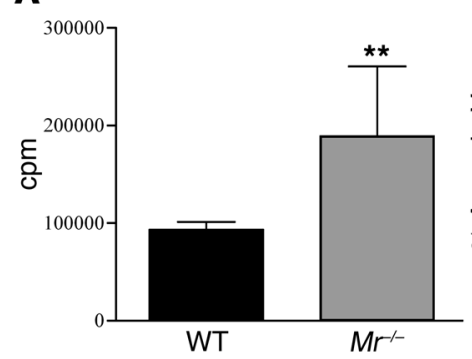

D

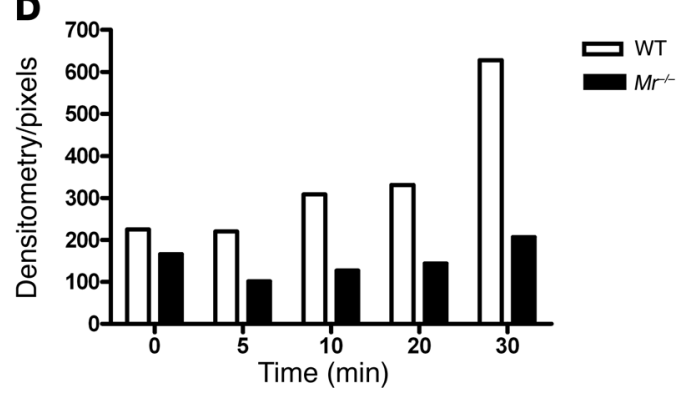

B

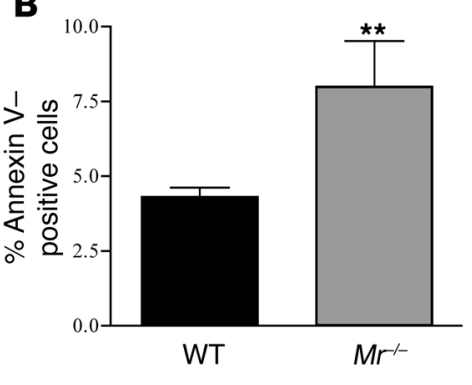

$\mathbf{E}$
C

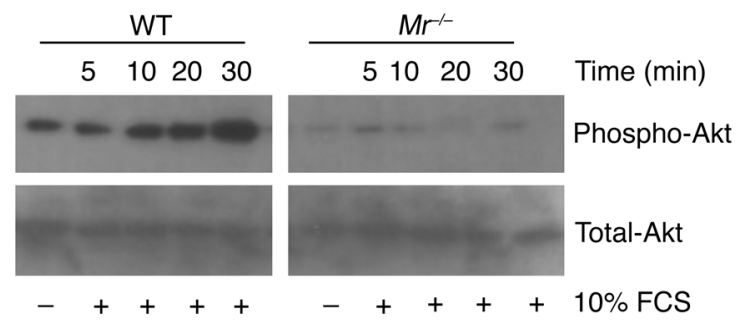

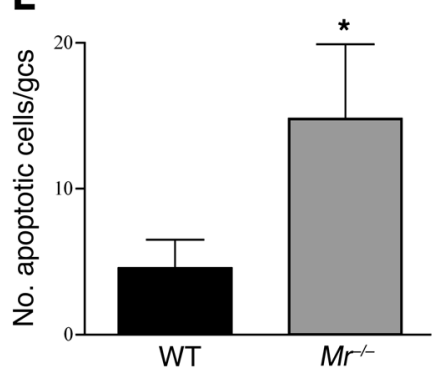

Figure 5

MR deficiency induces augmented MC proliferation and apoptosis. (A) Quantification of spontaneous MC proliferation by overnight tritiated thymidine incorporation. $\mathrm{Mr}^{-1-}$ cells displayed significantly greater rates of proliferation (in cpm) than did their WT counterparts. (B) Rates of apoptosis of cultured MCs, measured by annexin $\mathrm{V}^{+}$FACS staining, were significantly higher in $\mathrm{Mr}^{-1-}$ cells. (C) p-Akt and total Akt protein expression was assessed by Western blot in WT and $\mathrm{Mr}^{-1-} \mathrm{MC}$ lysates at basal levels and after stimulation with $10 \%$ FCS. (D) Densitometry of the bands showed that basal levels were lower in $\mathrm{Mr}^{-1-}$ cells and did not increase after exposure to $10 \%$ FCS, as they did in WT cells. (E) Increased MC apoptosis was found in vivo in $\mathrm{Mr}^{-1}$ mice with NTN. The number of TUNEL+ cells in glomeruli from kidneys of WT and $\mathrm{Mr}^{-1}$ animals at day 8 was scored and demonstrated significantly higher counts in $M r^{-1-}$ than WT mice. ${ }^{*} P<0.05 ;{ }^{* *} P<0.01$.

To our knowledge, MR deficiency has not previously been associated with a significant phenotype, except for the finding of elevated levels of certain circulating hydrolases in MR-deficient mice (30). $\mathrm{MR}$ is an endocytic receptor implicated in clearing autoantigens, glycosylated Igs, and foreign microbial compounds (31). It is therefore surprising that its deficiency was found to be associated with substantial protection from glomerulonephritis development. Whereas WT mice demonstrated severe glomerular inflammation, thrombosis, and tubulointerstitial inflammation, $M r^{-/-}$mice displayed well-preserved renal architecture, normal renal function, and minimal proteinuria. This protection occurred despite similar humoral and $\mathrm{T}$ cell immune responses, but was associated with diminished macrophage and $\mathrm{T}$ cell infiltration. Reduced lymphocyte recruitment to the lymph nodes and tumor cell metastasis has recently been reported in $\mathrm{Mr}^{/-}$mice and was found to be related to lymphatic MR expression, although dendritic cell migration and macrophage antigen presentation were not altered (32). Importantly, we found no evidence for renal dendritic cell expression of $\mathrm{MR}$, as has been previously described (27).

The present model of NTN is dependent on interaction of Igs with activatory FcRs $(33,34)$, as well as on macrophage- and $\mathrm{T}$ cell-mediated effector functions $(6,35)$. The mechanism of protection in $\mathrm{Mr}^{-1-}$ mice did not correlate with effector T cell function in terms of DTH responses, proliferation, or IL-17 production or with antibody generation. Importantly, because altered IgG glycosylation patterns have previously been associated with anti- or proinflammatory effects of Igs in this model (19), we confirmed that no differences in IgG glycosylation were present in the MRdeficient animals compared with their WT counterparts. In addi- tion, we have shown, for the first time to our knowledge, that the Fab fragment of sheep nephrotoxic globulin is capable of binding MR. Glycosylation of the Fab Ig region has long been known, with increased expression of $\mathrm{N}$-acetylglucosamine groups, and is thought to be critical in influencing antibody immunogenicity, efficacy, and clearance (36-38). Taken together with the colocalization of the 2 receptors, these findings lead us to conclude that $\mathrm{FcR}$ and MR could interact through the binding of nephrotoxic globulin. In addition, we demonstrated that, functionally, these 2 receptors interact, with $\mathrm{Mr}^{-/-}$macrophages and MCs displaying impaired Fc-mediated phagocytosis and oxygen burst activity compared with WT controls. These data support a previous report of an interaction between MR and FcR signaling, in which MR ligation promoted Fc-mediated phagocytosis (20). It is noteworthy that Fc $\gamma$ R-deficient animals are also protected from NTN and demonstrate reduced macrophage infiltration, which suggests that some non-FcR-mediated mechanisms allow macrophage recruitment (21). However, this is not the only mechanism underlying disease protection. An additional mechanism that could contribute to the resistance of $\mathrm{Mr}^{-1}$ to NTN is the immunosuppressive effect of increased numbers of apoptotic MCs on infiltrating macrophages. We demonstrated increased apoptosis in $\mathrm{Mr}^{--} \mathrm{MCs}$ at rest and after proinflammatory stimulation with LPS or IFN- $\gamma$ / TNF- $\alpha$. Furthermore, ingestion of apoptotic MCs by $\mathrm{Mr}^{-1-}$ macrophages induced a greater antiinflammatory response than in WT macrophages, with diminished TNF- $\alpha$ and increased IL-10 production, a signature suggesting a shift from a proinflammatory to an antiinflammatory or reparative phenotype. In our model, we also found evidence for augmented apoptosis in vivo in $\mathrm{Mr}^{--}$ani- 
A

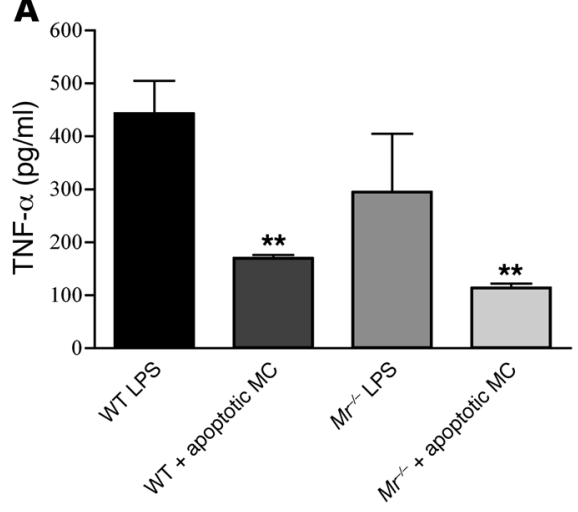

D

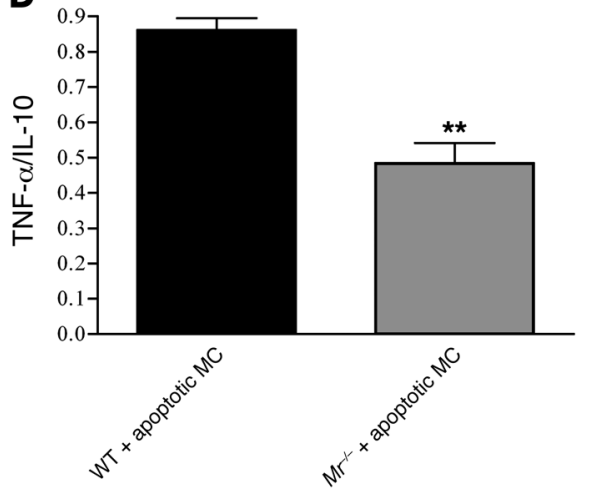

B

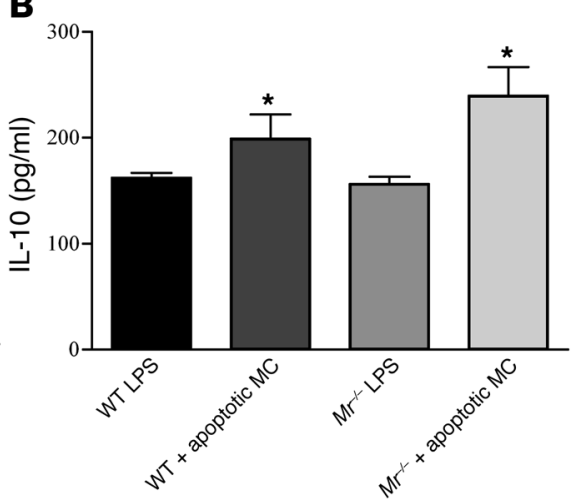

$\mathbf{E}$
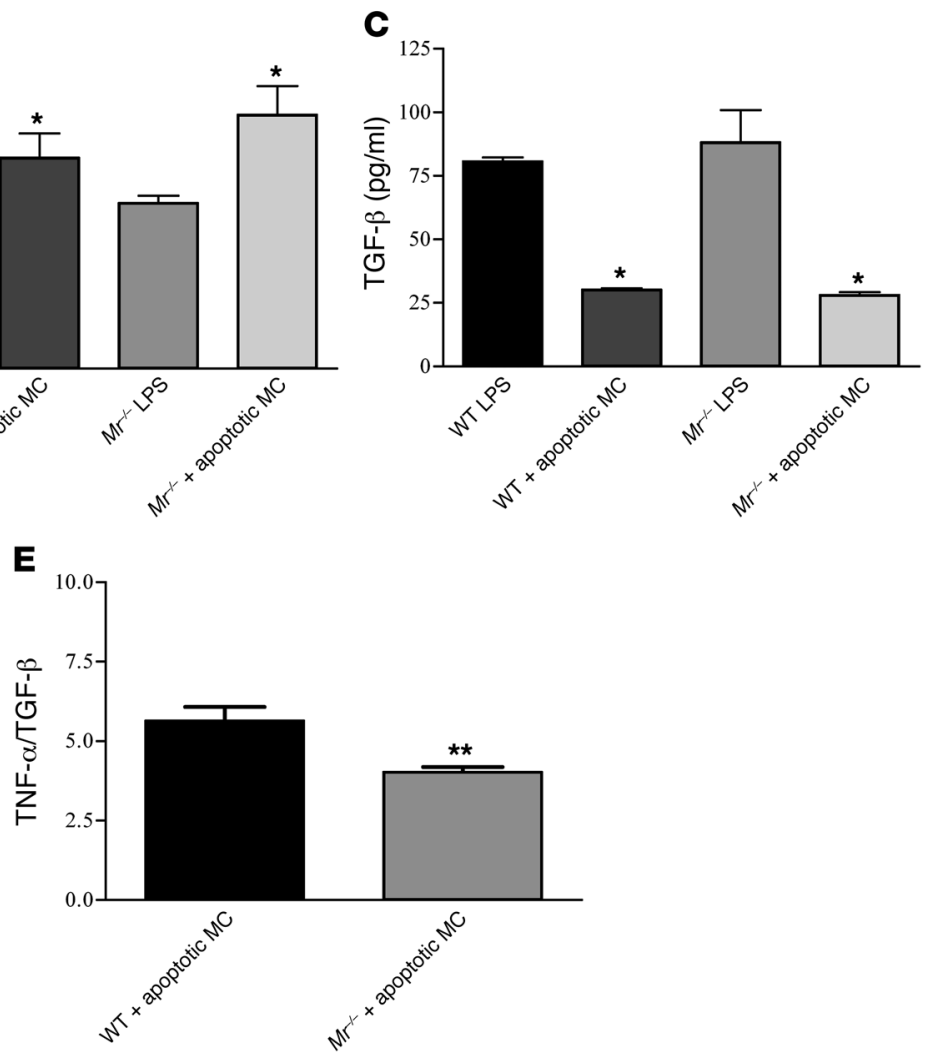

Figure 6

Cytokine release by WT and $\mathrm{Mr}^{-1}$ bone marrow-derived macrophages after stimulation with LPS and apoptotic WT MCs. Bone marrow-derived macrophages were incubated with $0.5 \mu \mathrm{g} / \mathrm{ml}$ LPS with or without apoptotic WT MCs. (A-C) Cultured supernatants were harvested 2 hours after macrophage stimulation and assessed for TNF- $\alpha$ (A), IL-10 (B), and TGF- $\beta$ (C). WT and Mr-1- macrophages reduced TNF- $\alpha$ production after uptake of apoptotic MCs, but the effect was significantly greater in $\mathrm{Mr}^{-1}$ cells. (D and E) TNF- $\alpha / \mathrm{LL}-10$ (D) and TNF- $\alpha / T G F-\beta$ (E) ratios confirmed a more significant noninflammatory phenotype in $M r^{-1-}$ than in WT cells. ${ }^{*} P<0.05 ;{ }^{*} P<0.01$.

mals, demonstrated by TUNEL staining of glomeruli. It should be noted that $\mathrm{Mr}^{-1}$ macrophages produced less TNF- $\alpha$ in response to a range of LPS doses compared with their WT counterparts, but after apoptotic particle uptake, there was a proportionally greater reduction in TNF- $\alpha$ in $\mathrm{Mr}^{-/}$cells.

Glomerular self-defense against invading leukocytes is not a new concept; others have suggested that alterations in MC cytokine/chemokine profiles could influence proinflammatory macrophages and prevent subsequent injury (39). Additionally, macrophage uptake of apoptotic particles has previously been shown to induce a less-inflammatory phenotype in vitro, with reduced production of cytokines such as TNF- $\alpha$ (40), but to our knowledge, these mechanisms have never been demonstrated to regulate NTN. A proposed mediator of such mesangial defence is TGF- $\beta$; however, we found no increase in TGF- $\beta$ production in $\mathrm{Mr}^{-/}$versus WT cells, which suggests that other, as-yet unknown, soluble factors may be responsible.

Importantly, our results may explain, at least in part, the unusual glomerulonephritis induced in $\alpha$-mannosidase II-deficient animals, which have diminished $\mathrm{N}$-glycan branching and express augmented mannose-bearing ligands in their circulation. These animals develop a spontaneous SLE-like autoimmune syndrome, with evidence of glomerulonephritis and MC activation, which are mannose binding dependent. Moreover, analogous to our findings, knockout animals do not display altered adaptive immune respons- es, whereas bone marrow chimeras with WT mice demonstrate that disease is dependent on a nonhematopoietic cell population (41).

One unexplained finding was that glomerular MR was downregulated after initiation of NTN, but was seen again at day 8. However, by day 3 after NTN, infiltrating MR-expressing macrophages were found in and around the glomeruli, and from then on, there appeared to be a difference in the development of glomerulonephritis between WT and $\mathrm{Mr}^{-/}$animals. Because WT mice with downregulated glomerular MR still expressed MR on the infiltrating macrophages, they behaved differently from $\mathrm{Mr}^{--}$animals. Therefore, early differences in the infiltrating macrophage phenotype predict differing outcomes in glomerulonephritis.

It appears that increases in mannose-bearing residues during inflammation or infection, or signaling through the MC or macrophage $\mathrm{MR}$, may lead to cell activation, augmented Fc-mediated responses, and glomerulonephritis promotion. Therefore, we believe MR represents a novel therapeutic target in immune-mediated glomerulonephritis, which, unlike conventional immunosuppressants, would not be associated with a profound depression in adaptive immune responses, potentially avoiding the significant adverse effects of systemic immunosuppression. We believe this mechanism may be applicable to other glomerular diseases, as our provisional data suggest that MR expression is upregulated in other forms of glomerulonephritis in both rodents and patients. 


\section{Methods}

Mice. $\mathrm{Mr}^{-/}$mice (30) were provided by M. Nussenzweig (Rockefeller University, New York, New York, USA). These mice were generated originally on a mixed strain of $129 \mathrm{SvJ}$ and C57BL/6 background, and were backcrossed to the C57BL/6 strain for more than 7 generations. Homozygous knockout mice were bred to provide experimental mice in the Biological Services Unit at Hammersmith Hospital. Mice used in this study were 8-12 weeks of age. Control age- and sex-matched C57BL/6 mice were obtained from Charles River Laboratories. The present studies were reviewed and approved by Imperial College Central Ethics Research Process Committee (Imperial College London) and were performed according to institutional guidelines.

Induction of accelerated NTN. Nephrotoxic globulin was prepared as described previously (42). Mice were preimmunized with $0.2 \mathrm{mg}$ sheep IgG in complete Freund adjuvant (Sigma-Aldrich) administered subcutaneously. Animals were injected 5 days later with $0.2 \mathrm{ml}$ nephrotoxic globulin via the tail vein, and disease was assessed 8 days later.

Histological analysis. Kidneys were fixed for 2 hours in buffered formalin, transferred to $70 \%$ ethanol, processed to paraffin, and stained with hematoxylin and eosin as well as periodic acid-Schiff reagent. Glomerular crescents and thrombosis were assessed by counting the involvement in 50 glomeruli per section and producing a mean glomerular involvement score for each mouse. Glomerular crescents were defined as glomeruli containing 2 or more layers of cells in Bowman's space and scored as severe glomerular involvement when present. Thrombosis was scored as severe when more than one-third of the glomerular tuft was involved. Thrombosis was also scored separately with a scale of $0-4$ representing quadrants of glomerular tuft involvement. Tubulointerstitial lesions were also graded on a $0-4$ scale according to the severity of tubular dilatation. The mean number of macrophages infiltrating the glomeruli was counted in 50 glomeruli per sample.

Immunohistochemical staining. For immunoperoxidase staining, kidneys were fixed for 4 hours in periodate lysine paraformaldehyde, washed overnight in $13 \%$ sucrose in PBS, and frozen in isopentane cooled with liquid nitrogen. Sections $(5 \mu \mathrm{m})$ were stained for macrophages with anti-CD68 $\mathrm{mAb}$ (FA-11; Serotec), for CD4 ${ }^{+}$cells with Ab GK1.5 (BD Biosciences - Pharmingen), and for MHC class II with M5/114 (provided by A. Dorling, Imperial College London). Polyclonal mouse anti-rat IgG was used as a secondary reagent, and rat peroxidase-anti-peroxidase was used as a tertiary antibody (Jackson ImmunoResearch Laboratories). The slides were developed in diaminobenzidine and counterstained with hematoxylin (Sigma-Aldrich). Apoptotic cells in paraffin sections were assessed by TUNEL staining using a TdT-FlagEL DNA fragmentation detection kit (Calbiochem) according to manufacturer's instructions.

Direct immunofluorescence was used to detect sheep and mouse IgG on sections of mouse kidney. FITC-conjugated sheep and mouse IgG (SigmaAldrich) and isotype controls were used for immunofluorescence staining. Sections were blocked with $20 \%$ serum from the species of the FITC-conjugated antibody for 30 minutes in order to block nonspecific cross-reactivity. The primary antibodies were diluted in PBS, spun down for 10 minutes at $7,600 \mathrm{~g}$, placed on the sections, and incubated for 1 hour at room temperature in a humidified chamber covered with aluminium foil. The sections were then washed 3 times in PBS and mounted in AF1 solution (Citiflur).

Serum creatinine and urea and proteinuria. Serum creatinine and urea were measured in the Department of Chemical Pathology, Hammersmith Hospital. Individual 24-hour samples of urine were collected using metabolic cages, with mice given free access to food and water. The urinary protein concentration was measured by using a Sulphosalicylic Acid Assay. On a 96-well ELISA plate (Fisher Scientific), 25\% sulphosalicylic acid was added to 2 wells $(10 \mu \mathrm{l} /$ well), and water was added to the third as blank $(10 \mu \mathrm{l} /$ well). BSA standards were made up in different dilutions to form a standard curve. Urine from animals $(10 \mu \mathrm{l})$, diluted $1: 10$ in distilled $\mathrm{H}_{2} \mathrm{O}$, was added to the wells in triplicate and left at room temperature for 10 minutes before reading the absorbance at a wavelength of $450 \mathrm{~nm}$. The level of proteinuria in the samples was then calculated by linear regression with reference to the BSA standard curve.

Mouse MC primary culture. Kidneys from WT or $\mathrm{Mr}^{-/}$animals were blended with a syringe plunger and forced through a series of sterile sieves with successively smaller pore sizes of 150,106 , and $45 \mu \mathrm{m}$. Glomeruli retained on the $45-\mu \mathrm{m}$ sieve were retrieved, washed in ice-cold PBS, and spun down at $145 \mathrm{~g}$ for 5 minutes. Glomeruli were digested with $380 \mathrm{U} / \mathrm{ml}$ collagenase (Sigma-Aldrich) for 30 minutes at $37^{\circ} \mathrm{C}$, spun down at $327 \mathrm{~g}$ for 5 minutes, and resuspended in DMEM-Glutamax culture medium (Invitrogen) supplemented with $15 \% \mathrm{FCS}, 100 \mathrm{U} / \mathrm{ml}$ penicillin, $100 \mathrm{~g} / \mathrm{ml}$ streptomycin, $1 \%$ insulin/selenium/transferrin growth supplement (ITS liquid; Sigma-Aldrich), and $20 \mathrm{mM}$ HEPES. Finally, glomeruli were plated on $0.1 \%$ fibronectincoated (Sigma-Aldrich) $25-\mathrm{cm}^{2}$ culture flasks and cultured at $37^{\circ} \mathrm{C}$ with $5 \%$ $\mathrm{CO}_{2}$. Medium was changed every 2-3 days thereafter. After glomerular cells reached confluence, they were passaged regularly using standard methods of serial culture and trypsinization. Passages 8-10 were used to perform experiments. MCs were characterized as previously described (43).

MC proliferation was assessed by $\mathrm{H}^{3}$ thymidine incorporation. $10^{6} \mathrm{cells} /$ well were cultured in a 6-well plate for 2 days in complete MC medium, after which $1 \mu \mathrm{Ci} \mathrm{H}^{3}$ thymidine was added for the last 18 hours of culture. Cells were washed twice in PBS and harvested with cell dissociation buffer (Sigma-Aldrich) before radioactivity was counted by a beta-counter (product no. 1450; Wallac MicroBeta Trilux; Perkin Elmer).

Mouse bone marrow-derived macrophages. Femurs were excised and washed in $70 \%$ ethanol, sterile PBS, and Hank medium (Sigma-Aldrich). Bones were transferred to a fresh Petri dish, where both ends were snapped and the bone marrow flushed out with 5-10 $\mathrm{ml} \mathrm{Hank}$ medium. Cells were washed 3 times with Hank medium, then resuspended in $20 \mathrm{ml}$ DMEM supplemented with $100 \mathrm{U} / \mathrm{ml}$ penicillin, $100 \mu \mathrm{g} / \mathrm{ml}$ streptomycin, 20\% FCS, 5\% conditioned macrophage media, and $1 \%$ ITS and cultured at $37^{\circ} \mathrm{C}$ in a total volume of $25 \mathrm{ml}$ in $140-\mathrm{mm}$ tissue culture Petri dishes (Marathon). On day 3 of culture, nonadherent cells were removed carefully, and fresh sterile culture medium was added. Macrophages were harvested on day 5 by washing with sterile PBS and incubation with $5 \mathrm{ml}$ cell dissociation buffer (Sigma-Aldrich) at $37^{\circ} \mathrm{C}$ for 10 minutes.

Phagocytosis assay. Latex polystyrene $2.0-\mu \mathrm{m}$ microspheres (20 or 50 beads/ macrophage; Polysciences Inc.) were incubated in $10 \mathrm{mg} / \mathrm{ml} \mathrm{BSA} \mathrm{(Sigma-}$ Aldrich) in PBS overnight at $4^{\circ} \mathrm{C}$. The beads were then washed 3 times in PBS and resuspended in $100 \mu \mathrm{l}$ PBS. Rabbit anti-bovine albumin, IgG fraction (Sigma-Aldrich), was added to a final dilution of 1:2 and incubated for 1 hour at room temperature. The beads were then washed 3 times in $1 \mathrm{ml}$ PBS and used immediately.

Macrophages were cultured as described above and plated in 8-well glass chamber slides at $10^{5}$ cells/well. Media was changed to serum-free media for 2 hours prior to adding the beads. Opsonized beads ( 20 or 50 beads/ macrophage) were added to macrophages and incubated at $37^{\circ} \mathrm{C}$ in $5 \%$ $\mathrm{CO}_{2}$ for 30 minutes. The media was then aspirated, and slides were stained with Diff-Quick fix (Dade Behring). Finally, 100 macrophages were counted to determine the number of beads ingested per cell.

Fc-mediated oxygen burst activity. Fc OxyBURST was used as previously described (44) to investigate Fc-mediated function. Briefly, cells $\left(1 \times 10^{6}\right.$ macrophages or MCs) were harvested and resuspended in Krebs-Ringer PBS (KRP buffer) with $1.0 \mathrm{mM} \mathrm{Ca}^{2+}, 1.5 \mathrm{mM} \mathrm{Mg}^{2+}$, and $5.5 \mathrm{mM}$ glucose, warmed to $37^{\circ} \mathrm{C}$ for 10 minutes, then stimulated with the Fc OxyBURST immune complex (120 $\mu \mathrm{g} / \mathrm{ml}$; Invitrogen). Fc OxyBURST-induced oxidative burst was assessed at different time points using flow cytometry to measure the percentage of fluorescent cells on a FACScalibur (BD Biosciences), analyzed using Cellquest software (BD Biosciences). 
Apoptotic cell phagocytosis. To induce apoptosis, MCs were either serumstarved for 24 hours or irradiated at 6.6 Gy and incubated for 12 hours in $10 \%$ FCS DMEM-Glutamax medium. Apoptosis was assessed by Annexin $\mathrm{V}$ labeling as described above. No significant necrosis was detected, as assessed by trypan blue exclusion ( $<1 \%$ positive). Macrophages were plated in 24-well culture plates in serum-free DMEM and cultured with apoptotic MCs (1:2 and 1:5 macrophage/MC ratio) in the presence of $0.5 \mu \mathrm{g} / \mathrm{ml}$ LPS (E. coli serotype 026:B6; Sigma-Aldrich) for 2 hours. Subsequently, the supernatants were collected, and macrophages were washed 3 times with cold PBS to remove unbound apoptotic MCs and LPS. Fresh serum-free DMEM was added to the macrophages for 24 hours, and the supernatants were collected once again.

Cytokine quantification. Sandwich ELISAs for mouse MCP-1, TNF- $\alpha$, IL-10, and TGF- $\beta$ (all R\&D Systems) were carried out according to the manufacturer's instructions.

Western blot analysis of Akt. MCs were serum-starved for 24 hours and then stimulated at different time points with $10 \%$ FCS. After removing the medium, cells were washed with PBS and lysed in ice-cold lysis buffer containing protease inhibitors (10 mM Tris- $\mathrm{HCl}, \mathrm{pH} 7.6$; 5 mM EDTA; $50 \mathrm{mM} \mathrm{NaCl} ; 30 \mathrm{mM}$ sodium pyrophosphate; $50 \mathrm{mM} \mathrm{NaF} ; 100 \mathrm{mM}$ $\mathrm{Na}_{3} \mathrm{VO}_{4} ; 1 \%$ Triton X-100; $5 \mathrm{mg} / \mathrm{ml}$ antipain; $1 \mathrm{mg} / \mathrm{ml}$ pepstatin; $5 \mathrm{mg} / \mathrm{ml}$ leupeptin; and $1 \mathrm{mM} \mathrm{PMSF}$ ) for 30 minutes at $4^{\circ} \mathrm{C}$. Lysates were harvested and centrifuged at $580 \mathrm{~g}$ to eliminate nuclei and stored at $-20^{\circ} \mathrm{C}$ until use. Protein concentration in lysates was quantified using a spectrophotometer, and $10 \mu \mathrm{g}$ lysates were then electrophoresed in a 10\% SDS-PAGE gel and transferred to polyvinylidene difluoride membranes (Millipore) overnight. The membrane was blocked with $5 \%$ nonfat milk/Tris-buffered saline (TBS) for 1 hour at room temperature and then incubated overnight with the primary antibody, rabbit anti-phospho-Akt, and rabbit anti-Akt (Cell Signalling Technology), both diluted 1:1,000 in 5\% milk, $1 \%$ BSA, and TBS. HRP-conjugated anti-rabbit IgG (Dako) was used as a secondary antibody at a dilution of 1:5,000. Bound antibody was detected using the ECL kit (Amersham Pharmacia Biotech) and visualized using Hyperfilm MP (GE Healthcare).

Analysis of $M R$ and FcR expression by flow cytometry and confocal microscopy. Confocal microscopy was used to assess the expression of MR on WT MCs and MR and CD16/32 expression on WT macrophages. Briefly, $0.3 \times 10^{6}$ WT MCs were added on chamber slides (Fisher) in complete medium for 24 hours. The slides were fixed in $4 \%$ paraformaldehyde on ice for 10 minutes, washed 3 times for 5 minutes in PBS, and permeabilized in $0.1 \%$ Triton X-100 in PBS for 10 minutes. Next, slides were washed again in PBS for 5 minutes, blocked with $10 \%$ rat serum in PBS, and incubated with $10 \mu \mathrm{g} / \mathrm{ml}$ of either PE-conjugated rat anti-mouse MR (5D3; Serotec) or PE-conjugated rat IgG $2 \alpha$ isotype control (Serotec) for 2 hours at room temperature. For colocalization of MR with CD16/32, $10^{5}$ macrophages were grown on chamber slides, washed 3 times in PBS, and blocked with $5 \% \mathrm{BSA} / 0.2 \%$ Tween 20 for 30 minutes. Rat anti-mouse MR (5D3; Serotec) or rat IgG $2 \alpha$ isotype control (Serotec) were incubated for 1 hour at room temperature. The slides were washed 3 times in PBS, and a secondary donkey anti-rat $\mathrm{Cy} 3$ (Jackson Immunoresearch) was applied at 1:500 dilution and left for 1 hour at room temperature. Slides were washed with PBS 3 times, and the CD16/32 FITC or rat IgG2b FITC was applied and left for 1 hour at room temperature. Finally, the slides were washed 3 times for 5 minutes in PBS and mounted with medium containing DAPI (Vector Laboratories). The analysis of the slides was done by a confocal microscope (Leica Microsystems).

Quantitative real-time PCR. Total RNA was extracted from WT and $\mathrm{Mr}^{-/}$ MCs using TRIzOL (Invitrogen), and $1 \mu \mathrm{g}$ was reverse transcribed to CDNA. Quantitative real-time PCR was then performed using Syber Green (AB Biosciences) and specific primers for Fcgr3b (forward, CAGTGAGATCCTGGGTTTAG; reverse, GTCTCTTGTTTAAAAATATA) and Gapdh (forward, ATCCCATCACCATCTTCCAG; reverse, CGCCCCACTTGATTTTGG).

Mass spectrometric analysis of IgG glycans. MALDI mass fingerprinting of the IgG N-glycans was carried out as described previously (45). Briefly, samples were reduced, carboxymethylated, and digested with trypsin. Glycans were released by digestion with PNGase F (Roche Applied Science), permethylated, and analyzed by MALDI-TOF on a Voyager-DE sSTR mass spectrometer (PerSeptive Biosystems).

Generation of Fab and Fc IgG portions. Pierce Fab micropreparation kit (Thermo Scientific) was used to generate and purify nephrotoxic globulin Fab and Fc portions according to the manufacturer's instructions.

$M R$ binding assays. Enzyme-linked immunosorbent assay plates (Nunc; Maxisorb) were coated with sugars (D-mannose-PAA or SO4-3- $\beta$-D-GalPAA; Lectinity Holding) or different protein preparations overnight at $4{ }^{\circ} \mathrm{C}$ in PBS. Wells were washed with TTBS (10 mM Tris-HCl, pH 7.4; $10 \mathrm{mM}$ $\mathrm{CaCl}_{2} ; 154 \mathrm{mM} \mathrm{NaCl}$; and $0.05 \%$ Tween 20). MR constructs (CTLD4-7-Fc and CR-FNII-CTLD1-3-Fc; refs. 18, 46) were then incubated at $1 \mu \mathrm{g} / \mathrm{ml}$ in TTBS, followed by incubation with a goat anti-human Ig Fc-specific antibody coupled to alkaline phosphatase diluted 1:1,000 (Sigma-Aldrich). Binding was measured at $405 \mathrm{~nm}$ after revealing with p-nitrophenyl phosphate substrate (Sigma-Aldrich) diluted in $100 \mathrm{mM}$ Tris- $\mathrm{HCl}$ ( $\mathrm{pH} 9.5$ ), $100 \mathrm{mM} \mathrm{NaCl}$, and $1 \mathrm{mM} \mathrm{MgCl}_{2} \bullet 6 \mathrm{H}_{2} \mathrm{O}$. For inhibition studies, incubation with $\mathrm{Fc}$ proteins was performed in the presence of $50 \mathrm{mM} \mathrm{D}$-mannose and $1 \mathrm{M} \mathrm{NaCl}$ as described previously (46).

Statistics. Results are expressed as mean \pm SD. Nonparametric tests of significance were applied throughout. To compare 2 groups, the Mann-Whitney $U$ test was used, and 3 or more groups were analyzed by 1-way ANOVA. GraphPad Prism (GraphPad Software) was used to analyze the data. Differences were considered significant at a $P$ value less than 0.05 .

\section{Acknowledgments}

K.-M. Chavele, J. Domin, H.T. Cook, C.D. Pusey, and A.D. Salama received support from the National Institute for Health Research (NIHR) Biomedical Research Centre Funding Scheme. A.D. Salama is supported by the NIHR. S. Gordon is supported by the Medical Research Council (MRC). A. Dell and S.M. Haslam are supported by grants BBF0083091 and B19088 from the Biotechnology and Biological Sciences Research Council (BBSRC).

Received for publication October 26, 2009, and accepted in revised form February 3, 2010.

Address correspondence to: Alan D. Salama, Renal Section, Division of Medicine, Imperial College London, Hammersmith Hospital, Ducane Road, London W12 0NN, United Kingdom. Phone: 44.208.383.3980; Fax: 44.208.383.3980; E-mail: A.salama@imperial.ac.uk.
1. Contreras G, et al. Sequential therapies for proliferative lupus nephritis. $N$ Engl J Med. 2004;350(10):971-980.

2. Jayne DR, et al. Randomized trial of plasma exchange or high-dosage methylprednisolone as adjunctive therapy for severe renal vasculitis. $\mathrm{J} \mathrm{Am}$ Soc Nephrol. 2007;18(7):2180-2188.

3. Xiao H, et al. Antineutrophil cytoplasmic autoan- tibodies specific for myeloperoxidase cause glomerulonephritis and vasculitis in mice. J Clin Invest. 2002;110(7):955-963.

4. Dean EG, et al. Experimental autoimmune Goodpasture's disease: a pathogenetic role for both effector cells and antibody in injury. Kidney Int. 2005;67(2):566-575.

5. Kalluri R, Danoff TM, Okada H, Neilson EG.
Susceptibility to anti-glomerular basement membrane disease and Goodpasture syndrome is linked to MHC class II genes and the emergence of T cell-mediated immunity in mice. J Clin Invest. 1997;100(9):2263-2275.

6. Duffield JS, et al. Conditional ablation of macrophages halts progression of crescentic glomerulonephritis. Am J Pathol. 2005;167(5):1207-1219. 
7. Ikezumi Y, Hurst LA, Masaki T, Atkins RC, Nikolic-Paterson DJ. Adoptive transfer studies demonstrate that macrophages can induce proteinuria and mesangial cell proliferation. Kidney Int. 2003;63(1):83-95.

8. Hill GS, et al. Predictive power of the second renal biopsy in lupus nephritis: significance of macrophages. Kidney Int. 2001;59(1):304-316.

9. Couser WG. Pathogenesis of glomerular damage in glomerulonephritis. Nephrol Dial Transplant. 1998;13 Suppl 1:10-15.

10. Duffield JS, Erwig LP, Wei X, Liew FY, Rees AJ, Savill JS. Activated macrophages direct apoptosis and suppress mitosis of mesangial cells. J Immunol. 2000;164(4):2110-2119.

11. Gordon S. Alternative activation of macrophages. Nat Rev Immunol. 2003;3(1):23-35.

12. Tam FW, Smith J, Karkar AM, Pusey CD, Rees AJ. Interleukin- 4 ameliorates experimental glomerulonephritis and up-regulates glomerular gene expression of IL-1 decoy receptor. Kidney Int. 1997;52(5):1224-1231

13. Shimizu A, Kitamura H, Masuda Y, Ishizaki M, Sugisaki Y, Yamanaka N. Apoptosis in the repair process of experimental proliferative glomerulonephritis. Kidney Int. 1995;47(1):114-121.

14. Baker AJ, Mooney A, Hughes J, Lombardi D, Johnson RJ, Savill J. Mesangial cell apoptosis: the major mechanism for resolution of glomerular hypercellularity in experimental mesangial proliferative nephritis. J Clin Invest. 1994;94(5):2105-2116.

15. Kitamura M, Suto T, Yokoo T, Shimizu F, Fine LG. Transforming growth factor-beta 1 is the predominant paracrine inhibitor of macrophage cytokine synthesis produced by glomerular mesangial cells. J Immunol. 1996;156(8):2964-2971.

16. Linehan SA, Martinez-Pomares L, Stahl PD, Gordon S. Mannose receptor and its putative ligands in normal murine lymphoid and nonlymphoid organs: In situ expression of mannose receptor by selected macrophages, endothelial cells, perivascular microglia, and mesangial cells, but not dendritic cells. J Exp Med. 1999;189(12):1961-1972.

17. McKenzie EJ, et al. Mannose receptor expression and function define a new population of murine dendritic cells. J Immunol. 2007;178(8):4975-4983.

18. Martinez-Pomares L, et al. Carbohydrate-independent recognition of collagens by the macrophage mannose receptor. Eur Immunol. 2006;36(5):1074-1082.

19. Kaneko Y, Nimmerjahn F, Ravetch JV. Anti-inflammatory activity of immunoglobulin $\mathrm{G}$ resulting from Fc sialylation. Science. 2006;313(5787):670-673.

20. Murai M, Aramaki Y, Tsuchiya S. Contribution of mannose receptor to signal transduction in $\mathrm{FC}$ gamma receptor-mediated phagocytosis of mouse peritoneal macrophages induced by liposomes. J Leukoc Biol. 1995;57(4):687-691.

21. Tarzi RM, et al. Nephrotoxic nephritis is mediated by Fcgamma receptors on circulating leukocytes and not intrinsic renal cells. Kidney Int. 2002;62(6):2087-2096

22. Lee SJ, Zheng NY, Clavijo M, Nussenzweig MC. Normal host defense during systemic candidiasis in mannose receptor-deficient mice. Infect Immun. 2003;71(1):437-445.

23. Swain SD, Lee SJ, Nussenzweig MC, Harmsen AG. Absence of the macrophage mannose receptor in mice does not increase susceptibility to Pneumocystis carinii infection in vivo. Infect Immun. 2003;71(11):6213-6221.

24. Akilov OE, Kasuboski RE, Carter CR, McDowell MA. The role of mannose receptor during experimental leishmaniasis. J Leukoc Biol. 2007;81(5):1188-1196.

25 . Sheryanna A, et al. Inhibition of p38 mitogen-activated protein kinase is effective in the treatment of experimental crescentic glomerulonephritis and suppresses monocyte chemoattractant protein-1 but not IL-1beta or IL-6. J Am Soc Nephrol. 2007;18(4):1167-1179.

26. Tam FW, et al. Urinary monocyte chemoattractant protein-1 (MCP-1) is a marker of active renal vasculitis. Nephrol Dial Transplant. 2004;19(11):2761-2768.

27. Lukacs-Kornek V, Burgdorf S, Diehl L, Specht S, Kornek M, Kurts C. The kidney-renal lymph node-system contributes to cross-tolerance against innocuous circulating antigen. J Immunol. 2008;180(2):706-715

28. Afonso L, et al. Interactions with apoptotic but not with necrotic neutrophils increase parasite burden in human macrophages infected with Leishmania amazonensis. J Leukoc Biol. 2008;84(2):389-396.

29. Serhan CN, Savill J. Resolution of inflammation: the beginning programs the end. Nat Immunol. 2005;6(12):1191-1197.

30. Lee SJ, et al. Mannose receptor-mediated regulation of serum glycoprotein homeostasis. Science. 2002;295(5561):1898-1901.

31. Gordon S. Pattern recognition receptors: doubling up for the innate immune response. Cell. 2002;111(7):927-930.

32. Marttila-Ichihara F, et al. Macrophage mannose receptor on lymphatics controls cell trafficking. Blood. 2008;112(1):64-72

33. Kaneko Y, Nimmerjahn F, Madaio MP, Ravetch JV. Pathology and protection in nephrotoxic nephritis is determined by selective engagement of specific Fc receptors. J Exp Med. 2006;203(3):789-797.
34. Tarzi RM, Davies KA, Claassens JW, Verbeek JS, Walport MJ, Cook HT. Both Fcgamma receptor I and Fcgamma receptor III mediate disease in accelerated nephrotoxic nephritis. Am J Pathol. 2003;162(5):1677-1683

35. Kitching AR, Holdsworth SR, Tipping PG. IFNgamma mediates crescent formation and cell-mediated immune injury in murine glomerulonephritis. J Am Soc Nephrol. 1999;10(4):752-759.

36. Lim A, Reed-Bogan A, Harmon BJ. Glycosylation profiling of a therapeutic recombinant monoclonal antibody with two N-linked glycosylation sites using liquid chromatography coupled to a hybrid quadrupole time-of-flight mass spectrometer. Anal Biochem. 2008;375(2):163-172.

37. Sox HC Jr, Hood L. Attachment of carbohydrate to the variable region of myeloma immunoglobulin light chains. Proc Natl Acad Sci U S A. 1970;66(3):975-982.

38. Taniguchi T, Mizuochi T, Beale M, Dwek RA, Rademacher TW, Kobata A. Structures of the sugar chains of rabbit immunoglobulin G: occurrence of asparagine-linked sugar chains in Fab fragment. Biochemistry. 1985;24(20):5551-5557.

39. Kitamura M, Fine LG. The concept of glomerular self-defense. Kidney Int. 1999;55(5):1639-1671.

40. Lucas M, Stuart LM, Savill J, Lacy-Hulbert A. Apoptotic cells and innate immune stimuli combine to regulate macrophage cytokine secretion. J Immunol. 2003;171(5):2610-2615.

41. Green RS, Stone EL, Tenno M, Lehtonen E, Farquhar MG, Marth JD. Mammalian N-glycan branching protects against innate immune self-recognition and inflammation in autoimmune disease pathogenesis. Immunity. 2007;27(2):308-320.

42. Robson MG, et al. Accelerated nephrotoxic nephritis is exacerbated in C1q-deficient mice. J Immunol. 2001;166(11):6820-6828.

43. Cortes-Hernandez J, et al. Murine glomerular mesangial cell uptake of apoptotic cells is inefficient and involves serum-mediated but complement-independent mechanisms. Clin Exp Immunol. 2002;130(3):459-466.

44. Behmoaras J, et al. Jund is a determinant of macrophage activation and is associated with glomerulonephritis susceptibility. Nat Genet. 2008;40(5):553-559.

45. Jang-Lee J, et al. Glycomic profiling of cells and tissues by mass spectrometry: fingerprinting and sequencing methodologies. Methods Enzymol. 2006;415:59-86.

46. Zamze S, et al. Recognition of bacterial capsular polysaccharides and lipopolysaccharides by the macrophage mannose receptor. J Biol Chem. 2002;277(44):41613-41623 